\title{
Effect of Sterilized Rumen Fluid Supplementation Ways in Lactation Period on Rumen Microflora of Calves after Weaning
}

\author{
Xueyan Lin ( $\nabla$ xueyanlin2005@163.com ) \\ Shandong Agricultural University https://orcid.org/0000-0003-1399-7674 \\ Tian Zhang \\ Shandong Agricultural University \\ Yue Jiang \\ Shandong Agricultural University \\ Qiuling Hou \\ Shandong Agricultural University \\ Yun Wang \\ Shandong Agricultural University \\ zhiyong $\mathrm{Hu}$ \\ Shandong Agricultural University \\ zhonghua Wang \\ Shandong Agricultural University
}

\section{Research article}

Keywords: Calves, Rumen fluid, Serum, Bacteria, Metabolites

Posted Date: September 4th, 2020

DOl: https://doi.org/10.21203/rs.3.rs-35613/v2

License: (c) (i) This work is licensed under a Creative Commons Attribution 4.0 International License. Read Full License 


\section{Abstract}

Background: The presence of the rumen makes the ruminant special, and the ruminal microbes has an important influence on the ruminant. The rumen have an important developed in young ruminants. This study want to investigate the ecological function of rumen fluid environmen from high-yielding dairy cows and effect of feeding of rumen fluid to suckling calves. For the experiment, 12 newborn Holstein male calves with the same feeding environment and similar ages were selected. They were randomly divided into 3 groups, with 4 in each group. The three treatments were: addition of sterilized rumen fluid to milk (Group M), addition of sterilized rumen fluid to starter feed (Group S), and control group fed milk and starter feed(Group C). The growth performance indices and blood indices were measured, and rumen fluid samples were collected after weaning,which used for 16S rDNA sequencing and LC-MS metabolome detection were performed.

Results: Compared with the control group, the growth performance of group $S$ was significantly increased. For the rumen fluid microbiome and metabolome detection, both groups $\mathrm{M}$ and $\mathrm{S}$ showed significant differences from group $\mathrm{C}$.

Conclusions: The microbes and metabolites were different due to different supplementary feeding methods. Metabolites with differential levels were mainly involved in metabolic pathways such as amino acid metabolism, nucleotide metabolism, and carbohydrate metabolism. These numerical differences indicate that there are specific ruminal microbes structures in the rumen fluid of high-yielding cows, which promoting better development of animals.

\section{Background}

Certain metabolites such as monosaccharides, amino acids and fatty acids have been shown to be major metabolites in rumen fluid $[1,2]$. These metabolites are necessary for microbial growth and are essential for the health of cattle. Rumen bacteria are coated with a thick layer of lipopolysaccharide (LPS) [3], but the effects of this substance on the ruminant immune system are mostly ignored. Studies in other animals have shown that lipopolysaccharides can induce the production of antibodies by providing more antigens. Macrophages are, in turn, induced to release cytokines that affect mammalian cell differentiation; avoidance of a cascade of immune stimuli is commonly referred to as oral tolerance $[4,5]$. Because rumen fluid contains multiple bacteria and other microorganisms [6], it also contain multiple LPS molecules.

In the rumen, there are many fiber-degrading bacteria that can degrade the plant feed to produce metabolites such as carbohydrate and protein, which in turn provide energy for the growth of other microorganisms. The growth of these fiber-degrading bacteria also requires $B$ vitamins, ammonia, acetic acid and valproic acid synthesized by other microorganisms. This relationship is necessary to maintain the rumen microflora and normal rumen function. Gylswyk found that when cultured in vitro with rumen fluid, some bacteria grew faster when a certain vitamin B was added to the rumen fluid. Therefore, some 
types of vitamin B may not be able to meet the growth needs of some specific bacteria[7]. Production of ammonia through decomposition of proteins and amino acids in the rumen is an important prerequisite for the synthesis of microbial proteins. Studies have shown that ammonia and butyric acid substances produced by Prevotella degradation of casein can be utilized by Ruminococcus albus [8]. Muscato conducted four tests to infuse different rumen fluid in 6-week-old calves at a dose of $8 \mathrm{~mL} /$ day by adding rumen fluid to milk. The rumen fluid fed in the experiment included fresh rumen fluid, supernatant of rumen fluid, cells of rumen fluid and rumen fluid sterilized by high-pressure steam[9]. The results prove that the rumen contents can promote the normal development of the rumen.

Under the intervention of exogenous rumen microflora and diet, the adult rumen microflora had strong anti-interference ability and restored the original components[10], indicating that it product beneficial effects in adult life through early life intervention on microbes. In fact, the change of rumen microbes have successfully achieved long-lasting results through intervene diet of Young ruminant[11,12]. In the past, dietary intervention strategies was mainly used to alter the rumen microbes but it's inefficient for adult ruminants, which has led to increasing interest in understanding microbial interactions in the rumen of young ruminant [13]. It has been reported that restricting access to protozoa in the early life of lambs also changes rumen microbial composition and fermentation as well as urine metabolites [14]. Therefore, these studies suggest that changes in the early rumen microbiota may affect the microbial succession process, and change the host phenotype.

\section{Results}

\section{Growth performance results}

Table 2 shows the effects of the supplemental sterilized rumen fluid treatments on growth and feed intake of the calf. There was no significant difference in the growth index of the calves between the groups before the test $(P>0.05)$. Within ten weeks, the daily weight gain of the $S$ group was significantly higher than that of the $C$ group $(P<0.05)$.

\section{Serum index results}

Table 3 shows the changes in the calf serum index in each group. Due to differences among the individual test animals, the calf serum index (supplementation 1) between the groups before the test was statistically different, and this difference could not be avoided. Therefore, the change in serum results was statistically analyzed. The numerical magnitude represents the amount of change at two points in time, positive or negative indicating an increase or decrease. A comparison was made between after treatment and after treatment for a period of time, the first stage was from 7 days to 15 days of age; the second stage was from 15 days to 63 days of age. It can be seen from table 3 that the experimental treatment had significant effects for most of the indicators during the two stages, but the effect on TNF-a was not significant in the first stage and IgG in the second stage. The serum IL-1 $\beta$ increased in all the experimental groups, but the changes in $\mathrm{M}$ group and $\mathrm{S}$ group were significantly lower than that in group $\mathrm{C}(P<0.05)$. In the second stage, the $\mathrm{C}$ group showed an increasing trend, whereas the $\mathrm{M}$ and $\mathrm{S}$ groups 
showed significant decreasing trends $(P<0.05)$. Serum TNF-a showed an increasing trend in all the firststage trials, the second-stage $M$ and $S$ groups showed a decreasing trend, and the change was significantly different from that of the $\mathrm{C}$ group $(P<0.05)$. The amounts of serum IL-4 in M and S groups during the first stage were significantly lower than that in the $C \operatorname{group}(P<0.05)$. Serum IFN- $y$ decreased in all the groups in the first stage, but the decrease in the $\mathrm{M}$ group was significantly lower than that in the $\mathrm{C}$ group. Serum LP showed an increasing trend for all treatment groups in the first stage, while group $C$ showed a downward trend; the amount of change was significantly different $(P<0.05)$.

\section{S rDNA sequencing results}

\section{Single sample diversity analysis}

From Figure 1, we found that the dilution curves of all samples tended to be flat, indicating that the samples were adequately sequenced and the depth covered almost all species in the sample.

\section{OTU analysis}

The tags were clustered at the $97 \%$ similarity level to obtain OTU, and OTU was classified based on the Silva (bacteria) taxonomy database to obtain the OTU number of each sample. A total of 355 OTUs were obtained from 12 samples. There were 337 OTUs in the control group, with 315 OTUs in groups M and S. It can be seen from the Venn diagram that 280 of the OTUs were shared between the three groups; 19 OTUs were only in group C, 1 OTUs was only in group $\mathrm{M}$, and 3 OTUs were only in group S (Fig. 2).

\section{Species annotation and taxonomic analysis}

The OTU representative sequence was compared with the microbial reference database to obtain species classification information corresponding to each OTU. Furthermore, the composition of each sample community was counted at each level (phylum, class, order, family, genus, species), and the abundance for each species at different classification levels was obtained.

At the phylum level, 11, 11, and 10 phyla were detected in rumen fluid of groups $C, M$, and $S$, respectively (Figure 3). Group C contained $49.95 \%$ of Bacteroidetes, $32.06 \%$ of Firmicutes, $13.19 \%$ of Proteobacteria, $1.64 \%$ of Fibrobacteres, and $2.31 \%$ of Teneriquets. Group M contained $38.07 \%$ of Bacteroidetes, $48.04 \%$ of Firmicutes, $11.98 \%$ of Proteobacteria, $0.50 \%$ of Fibrobacteres, $0.22 \%$ of Teneriquets, and $0.60 \%$ of Cyanobacteria. Group S mainly contained $52.41 \%$ of Bacteroidetes, $34.37 \%$ of Firmicutes, $6.80 \%$ of Proteobacteria, $4.46 \%$ of Fibrobacteres, and $0.61 \%$ of Teneriquets.

At the genus level, 122, 124 and 124 genera were detected in the rumen fluid of groups $C, M$ and $S$, respectively (Figure 4). Group C mainly contained $15.40 \%$ of Prevotella_7, $24.22 \%$ of Prevotella_1, $10.93 \%$ of Succinivibrionaceae_UCG-001, 9.80\% of Roseburia. Group M mainly contained $24.79 \%$ of Prevotella_7, $6.14 \%$ of Prevotella_1, $10.70 \%$ of Succinivibrionaceae_UCG-001, 9.51\% of Xiaoster, $7.27 \%$ of Ruminococcaceae_UCG-014 and $7.26 \%$ of Megasphaera. Group S mainly contained $38.55 \%$ of 
Prevotella_7, $1.77 \%$ of Prevotella_1, 4.14\% of Succinivibrionaceae_UCG-001, $6.22 \%$ of Roseburia, $7.28 \%$ of Dialister and $6.08 \%$ of Ruminococcaceae_UCG-014.

\section{Ternary phase analysis}

From Figure 5, we can see the proportion and relationship of different species among the three groups. Proteobacteria had the largest proportion in group $\mathrm{C}$ and the smallest proportion in group $\mathrm{S}$.

Fibrobacteres and Bacteroidetes have the largest proportion in group S and extremely small in group $\mathrm{M}$. Tenericutes has the largest proportion in group $\mathrm{C}$ and the smallest proportion in group $\mathrm{M}$, whereas Firmicutes have the largest proportion in group $\mathrm{M}$ and the smallest proportion in group $\mathrm{C}$.

\section{Significant difference analysis between sample groups}

Table 4 shows the taxonomic statistics of bacteria within rumen fluid with contents greater than $0.01 \%$ in groups $\mathrm{C}$ and $\mathrm{M}$, among which, there are significant differences between Firmicutes, Ruminococcaceae, uncultured_bacterium_o_Gastranaerophilales, p-2534-18B5_gut_group, Oxalobacteraceae, uncultured_bacterium_o_Gastranaerophilales, [Eubacterium]_coprostanoligenes_group, Oxalobacter, Dialister.

Table 5 shows the taxonomic statistics of bacteria within rumen fluid with contents greater than $0.01 \%$ in groups $\mathrm{C}$ and $\mathrm{S}$, among which, there were significant differences between Deltaproteobacteria, Desulfovibrionales, uncultured_bacterium_o_Gastranaerophilales, Desulfovibrionaceae, Oxalobacteraceae, Ruminococcaceae_NK4A214_group, uncultured_bacterium_o_Gastranaerophilales, uncultured_bacterium_f_Erysipelotrichaceae, Desulfovibrio, Dialister, [Ruminococcus]_gauvreauii_group, Mitsuokella, Prevotella_7.

Table 6 shows the taxonomic statistics of bacteria with rumen fluid bacteria content greater than $0.01 \%$ in groups $\mathrm{M}$ and $\mathrm{S}$, among which, there were significant differences between Syntrophococcus, Rikenellaceae_RC9_gut_group, p-2534-18B5_gut_group, [Ruminococcus]_gauvreauii_group, uncultured_bacterium_f_p-2534-18B5_gut_group, Pyramidobacter]Prevotella_7.

\section{Metabolomics analysis}

\section{Metabolite volcano map analysis}

The volcano map can be used to quickly view the differences in metabolite expression levels between the two groups, as well as the statistical significances of these differences. The differential expression volcano is as follows: Compared with group $\mathrm{C}$, group $\mathrm{M}$ had 42 significant metabolites in positive ion mode, of which, levels of 3 were significantly down and levels of 39 were significantly up; There were 5 significant metabolites in negative ion mode, of which the level of 1 was significantly down and levels of 4 were significantly up. Compared with group C, group S had 38 significant metabolites in positive ion mode, of which, levels of 9 were significantly down and levels of 29 were significantly up; There were 27 
significant metabolites in negative ion mode, of which, levels of 10 were significantly down and levels of 17 were significantly up (Figure 7).

\section{Analysis of differential metabolites and metabolic pathways}

As can be seen from table 7, compared with group $\mathrm{C}$, levels of some metabolites in group $\mathrm{M}$ were significantly increased, including 5-methylcytosine, xanthine, L-citrulline, myo-inositol, 2-isopropylmalic acid, 3-methoxy-4-hydroxyphenylethyleneglycol, indoleacetic acid, deoxyadenosine, erucic acid, UDP-Dgalactose, uracil, and homovanillic acid. The main metabolic pathways involved include: pyrimidine metabolism (ko00240), purine metabolism (ko00230), biosynthesis of amino acids (ko01230), arginine biosynthesis (ko00220), ascorbate and aldarate metabolism (ko00053), inositol phosphate metabolism (ko00562), galactose metabolism (ko00052), 2-oxocarboxylic acid metabolism (ko01210), valine, leucine and isoleucine biosynthesis (ko00290), pyruvate metabolism (ko00620), tyrosine metabolism (ko00350), tryptophan metabolism (ko00380), unsaturated fatty acid biosynthesis (ko01040), galactose metabolism (ko00052), amino sugar and nucleotide sugar metabolism (ko00520), $\beta$-alanine metabolism (ko00410); pantothenic acid and CoA biosynthesis (ko00770). Significantly down metabolites include: myristic acid, thiamine, and the major metabolic pathways involved: fatty acid biosynthesis (ko00061), thiamine metabolism (ko00730).

As can be seen from table 8, compared with group C, levels of some metabolites in group S were significantly increased, including cytidine, D-ribulose 5-phosphate, ergothioneine, thymidine 5'monophosphate, cytidine 5'-monophosphate, UDP-D-galactose, uracil, urocanic acid, xanthine, N- acetyl-Lglutamate, salidroside. The main metabolic pathways involved include: pyrimidine metabolism (ko00240), pentose phosphate pathway (ko00030), vitamin B6 metabolism (ko00750), riboflavin metabolism (ko00740), carbon metabolism (ko01200), amino acid biosynthesis (ko01230), pentose and glucuronic acid (ko00040), histidine metabolism (ko00340), amino sugar and nucleoside sugar metabolism (ko00520), galactose metabolism (ko00052), pantothenate and CoA biosynthesis (ko00770), $\beta$-alanine metabolism (ko00410), purine metabolism (ko00230), 2-oxocarboxylic acid metabolism (ko01210), arginine biosynthesis (ko00220), tyrosine metabolism (ko00350). Metabolites with significantly decreased levels include: 5-Aminopentanoic acid, and the major metabolic pathways involved: arginine and proline metabolism (ko00330), lysine degradation (ko00310).

\section{Discussion}

\section{Effect of feeding rumen fluid on the growth of calves}

Muscato supplemented calves with different treatments of rumen fluid from healthy cows. The results showed that supplemental feeding of rumen fluid significantly increased calf body weight gain during the first 2 weeks $(P<0.05)$ [9]. Zhang Lihua supplemented lambs with rumen fluid preparations, and increased the daily gain of lambs in the experimental group. James gave newborn yak calves duodenal juice along with the initial colostrum feeding. The results showed that feeding duodenal juice can increase the daily gain of 7-day-old yak after birth [15]. The results of ours experiment showed that supplemental feeding of 
rumen fluid could improve the growth performance of calves to a certain extent. From the numerical point of view, supplemental feeding of rumen fluid with milk is better than starter.

\section{Effect of feeding rumen fluid on calf serum}

$\operatorname{Ig} A$ cannot pass through the placenta, and there is no $\lg A$ antibody in the newborn calf serum, which will gradually increase after birth and account for a small amount of total serum immunoglobulin. Serum IgG is the major antibody component of serum and accounts for the majority of serum immunoglobulins. The content of $\lg A$ and $\lg G$ in serum can reflect the establishment of the animal's immune system. The first phase of the test was from 7 days to 15 days, and at this stage, the calves are no longer passively immunized by colostrum; during this phase, IgG decreased in the control group, which may be related to this. In the experiment, supplementing with rumen fluid may increase the serum IgG content at this stage. In the first stage, TNF-a increased in each group, but the changes in groups $M$ and $S$ were greater than those in group C. Lipopolysaccharide (LPS) is a component of the cell wall of Gram-negative bacteria, and strongly stimulates production of TNF-a. TNF-a can directly kill tumor cells and is not toxic to normal cells. The rumen fluid of group $\mathrm{M}$ and group $\mathrm{S}$ may contain LPS. IFN- $\gamma$ has antiviral, immunomodulatory and antitumor properties, and its concentration positively correlates with viral load. In the first stage, the IFN- $y$ of all experimental groups showed a downward trend; during the second stage, group M still showed a downward trend while the other groups showed an increasing trend. These test results show that in some indicators, the supplemental feeding and ways of the sterilized rumen fluid will have certain influence on the serum index, and may have a beneficial effect on calves, but the mechanism needs further research.

\section{Effect of feeding rumen fluid on microbes in rumen fluid of calves}

The main microflora in the rumen fluid samples of groups $\mathrm{M}, \mathrm{S}$ and $\mathrm{C}$ were Proteobacteria, Bacteroidetes and Firmicutes, and these results are consistent with a previous calf study of rumen microflora on days 15-83 [16]. The rumen bacteria of unweaned calves mainly consist of three phyla: Bacteroidetes, Firmicutes and Proteobacteria. After weaning, the gastrointestinal tract develops and matures, and the abundance of each phyla may vary with different stages; however, these three phyla remain the most abundant [17]. The relative abundances of Oxalobacter and Dialister in groups $\mathrm{M}$ and $\mathrm{S}$ were significantly higher than those in group $\mathrm{C}$, and Oxalobacter was not detected in group $\mathrm{C}$. It has been reported that the relative abundances of Oxalobacter and Dialister are significantly increased in patients with diarrhea treated with probiotics [18]. In a bacterial colonization treatment of patients with inflammatory bowel disease (IBD), four microbial phylotypes were found in the intestinal tract of a patient with Crohn's disease (CD) who experienced transient remission, including Dialister. This study also suggested that the absolute abundance of bacteria in fecal samples used for microflora transplantation could indicate the success of transplantation rather than the overall abundance relative to the recipient [19]. Selenomona was not detected in group $\mathrm{M}$ and group $\mathrm{S}$, while it could be detected in group $\mathrm{C}$. Studies have shown that the addition of a composite antimicrobial peptide reduces the genus Selenomona, which is associated with the degradation of starch [20]. The abundance of Firmicutes in group M was significantly higher 
than that in group $\mathrm{C}$. Firmicutes have been shown to have cellulose and hemicellulose degrading enzymes $[21,22]$. Firmicutes mainly hydrolyze carbohydrates and proteins. Bacteroidetes mainly act on steroids, polysaccharides and bile acids, which help the body to absorb polysaccharides and perform protein synthesis $[23,24]$. Studies have found that the abundance of Firmicutes increases after weaning of male calves [17]. The Rumencoccaceae family in group $\mathrm{M}$ was significantly higher than in group $\mathrm{C}$. The Rumencoccaceae family was originally a benign species inhabiting the cecum and colon [25] and has been shown to degrade a variety of polysaccharides and fibrils [26], and represents the main fibrinolytic bacteria in the rumen. Compared with normal rat fecal flora, Rumencoccaceae is significantly reduced in colon cancer rats [27]. Studies suggest that with increasing age, there is a significant increase in the abundance of p2534-18b5_gut_group in the rumen of northern shaanxi white cashmere goats [28]. Although adult cow rumen fluid was introduced into calves of group $M$, the p2534-18b5_gut_group in our study was significantly lower than that in group C. 16S rRNA analysis found that the intracellular Campylobacter-like organism (ICLO) of porcine proliferative enteropathy is closely related to desulfurization of Desulfovibrio[29], which can also be obtained from the rumen of sheep [30] and the human intestine[31,32]. Desulfovibrionales in Group M were significantly lower than in Group C; it is suggested that Mitsuokella may inhibit the growth of Salmonella in the gut [33], and interestingly, Mitsuokella was significantly lower in group $S$ than in group C. Prevotella is usually found in the rumen of herbivores such as cattle and sheep, and the most abundant strain is also found in the human gut. It is known to contain enzymes that degrade various polysaccharides (including xylan)[34] and is a starchdegrading bacterium. Prevotella also plays a role in the degradation of proteins and the absorption and fermentation of peptides in the rumen. The abundance of Prevotella_7 in group S was significantly higher than in group C. Lactobacillus paracasei LC01 can significantly improve the intestinal Ruminococcaceae_UCG014 in mice when introduced by gastric irrigation [35]. The relative abundance of Ruminococcaceae NK4A214 group and Ruminococcaceae UCG -014 increased with increasing feed NDF levels [36]. The abundance of Ruminococcaceae UCG-014 in group S was significantly higher than in group $C$, but the abundance of Ruminococcaceae NK4A214 group was significantly lower in group $S$ than group C. Synergistetes is a strict gram-negative anaerobic bacterium, and the abundance of ruminal Syntrophococcus is significantly increased with rumen acidosis . Calves fed starter supplemented with rumen fluid, which would enter the rumen. After weaning, the rumen fluid microbes of the $S$ group produced significant differences relative to group $C$ in the abundances of some species. It is speculated that the rumen fluid directly enters the rumen and directly contacts the internal microorganisms and the rumen, thus affecting the rumen microorganisms. These differential microbial species may become the focus of the "peripheral microbe" species which are affected by the environment. The rumen fluid supplementation of calves in group $\mathrm{M}$ was added through milk. We believe that milk bypasses the rumen and directly enters the abomasum due to the oesophageal groove in calves; however, no studies have shown that the addition of other ingredients in milk affects the closure of the oesophageal groove. After weaning, the abundances of some rumen fluid microflora species in group $\mathrm{M}$ were also significantly different from those in group $\mathrm{C}$, but these species were in complete accordance with those in group $\mathrm{S}$. The results suggested that rumen fluid entering the abomasum may have some effects on the host, and the changes in host metabolism may also act on the rumen, indirectly changing the microflora in the 
rumen. These different microbial species may become the focus of studies on the "core microbial" species affected by the host. It can be seen from this experiment that the addition of high-yield cow rumen fluid in milk and starter diet can positively affect growth on the basis of maintaining normal rumen microorganisms. However, due to the different paths the rumen fluid entered the body, there were differences in microorganism populations enhanced by the two supplementary feeding methods.

\section{Effects of rumen fluid supplementation on rumen fluid metabolites and metabolic pathways in calves}

After the addition of rumen fluid in milk and starter, the metabolites related to nucleotide metabolism, amino acid metabolism, carbohydrate metabolism, lipid metabolism, coenzyme and vitamin metabolism in rumen fluid metabolites of calves significantly increased, while some metabolites significantly decreased. Among them, the main effects involved nucleotide metabolism, amino acid metabolism and sugar metabolism pathways.Lipid metabolism pathway associated myristic acid and coenzyme vitamin metabolic pathway associated thiamine were significantly reduced in group M. In group S, no differential metabolites related to lipid metabolism pathway were found and the 5-aminopentanoic acid associated with the amino acid metabolic pathway was significantly reduced. In amino acid metabolism, the carbon framework remaining after amino acid deamination can be used for the synthesis of various volatile fatty acids, and bacterial deamination can serve as an energy source for these bacteria. Bladen was isolated from a group of strains with high ammonia-producing activity and polysaccharide degradation activity, which could be maintained by fermentation of amino acids [37]. Ciliate has a strong deamination effect and the deamination of ciliate is mainly targeted at some amino acids of lesser abundances, such as citrulline, arginine and ornithine. In addition, protozoa can degrade amino acids to produce other products, such as thio-methionine to alpha-aminovaleric acid. In the process of bacterial growth, different bacteria use different amino acids, which alters the mode of amino acid deamination mode when the animals eat different diets, and this relates to the bacterial species in the rumen. Mcallan did an in vitro experiment on the degradation of nucleic acids in rumen fluid. Pyrimidine nucleotides can form uracil and thymine, and cytosine can become uracil after deamination. Purine nucleotides can form hypoxanthine nucleotides and xanthine[38]. Nucleotide degradation by protozoa mainly depends on nucleotides derived from rumen bacteria. Gs studies on protozoa found that Entodinium caudatum and Eudiplodinum maggii can convert adenine and guanine into hypoxanthine and jaundice, and Entodinium caudatum can absorb bacterial nucleotides [39]. Some rumen bacteria can use adenine and guanine as nitrogen sources, and this ability may be related to the deamination and utilization of the released ammonia. Many rumen bacteria also produce extracellular nucleases, and these may be involved in the degradation of DNA. Carbohydrates in the rumen are degraded in two stages: initially, they are degraded into simple sugars by various enzymes; they are subsequently used by microorganisms in the rumen; finally, they are converted into acetone for fermentation through various metabolic pathways. The arginine metabolic pathway has been linked with many bacteria[40,41] and Pseudomonas [42,43]in previous studies. Involvement of a novel transaminase family in the arginine biosynthesis pathway has been previously reported [44]. In xanthomonas, $\mathrm{N}$-acetylornithine is converted to $\mathrm{N}$-acetylcitrulline by an enzyme encoded by arg $\mathrm{F}^{\prime}$ [45]. Arg $\mathrm{E}$ deacetylates $\mathrm{N}$-acetylcitrulline to form citrulline. Xylella, Bacteriodes, Cytophaga, and fungi contain homologs of $\arg \mathrm{F}^{\prime}$. The Bacteroides fragilis Arg $\mathrm{F}^{\prime}$ is essential for the biosynthesis of arginine 
[46].Through the combined analysis of microbial-metabolite-metabolic pathway, we found that I-citrulline ( $L$-Citrulline) in group $M$ was significantly higher than that in group $C(P<0.05)$. It was involved in the arginine biosanabolism pathway, and it was also related to the bacteria Prevotella_7 and Odoribacter in the gastric fluid of tumor, both of which belong to bacteroides. Ergosine (EGT), which has immunomodulatory effects[47], can be synthesized by non-yeast fungi, some Actinomycetes bacteria and Cyanobacteria, but not in animals [48]. M. smegmatis can produce EGT gene (egtA, egtB, egtC, egtD, egtE). EgtD has been proved to be a histidine methyltransferase, which converts histidine into histidine trimethionine through S-adenosylmethionine [49]. Studies have shown that rumen bacteria degrade histidine, producing uric acid, $\mathrm{N}$-formamide-glutamic acid, formamide and glutamic acid [50]. Uric acid is an intermediate in the normal catabolism of histidine. The idea that free amino acids are intermediates in the breakdown of proteins by rumen microorganisms has been widely accepted. In addition, there is a large amount of circumstantial evidence that the intermediates of the degradation process are also important substrates for biosynthetic processes of rumen microorganisms [51]. Many substances related to amino acids, saccharide and nucleotides were detected in rumen fluid of calves in group $M$ and group $\mathrm{S}$ at higher concentrations than those in group $\mathrm{C}$. These amino acids can be used as substrates for the synthesis of microbial proteins, and carbohydrates can provide energy for the synthesis of microbial proteins. This suggests that calves may gain more microbial proteins due to increased metabolism in many metabolic pathways by rumen fluid supplementation.

\section{Conclusions}

Sterilized rumen fluid supplementation during the lactation period can promote the growth of calves after weaning. It is better to feed through starter than through milk. Both supplementation methods have an effect on the microbiome and metabolome of calf rumen fluid, but the effects of the two methods are different. The two supplementation methods involved entry of rumen fluid into different parts of the body, thereby having differential effects on microorganisms. Therefore, it can be seen that the host can affect the rumen microorganisms.

\section{Methods}

\section{Test design}

For the experiment, 12 newborn Holstein male calve of similar age were single column feed and accepted the same feeding regimen. They were randomly divided into 3 groups on average. The treatments were as follows: addition of sterilized rumen fluid to milk (Group M), addition of sterilized rumen fluid to starter feed (Group S), and fed only milk and starter as control group (Group C). They were fed twice a day and water free. The $20 \mathrm{~mL}$ sterilized rumen fluid was added to their diet at the every day of the second week. The sterilized rumen fluid was extracted from a adult cow with an oral sampler; it filtered through four layers of gauze, decanted into a sterile cryotube, placed in an ultra-low temperature freezer, and repeatedly frozen and thawed 10 times. The repeated freezing and thawing uses the ice crystals inside the microorganisms to break their cell walls through the mechanical action of freezing-thawing, releasing 
some cellular components but avoiding the destruction of rumen fluid components by chemical reagents or high temperature. The processed rumen fluid was added to the milk and the starter to supplement the calves in groups $\mathrm{M}$ and $\mathrm{S}$, respectively.

All calves come from Jinan High speed pastures and they were single column feed.

\section{Calves feeding management}

After birth, the umbilical cord was soaked in $7-10 \%$ of iodine, and birthweight was determined. Highquality pasteurized colostrum was fed, for a total of $4 \mathrm{~L}$ in the first hour (8-10\% of calf body weight), and an additional 3-4L of colostrum was fed in 6-8 hours to ensure that the calf has 6-8L colostrum in 12 hours; colostrum was provided at 36 to $40^{\circ} \mathrm{C}$ temperature. Normal milk was fed 8 hours after feeding colostrum, and was provided twice daily at 7:00 am and 15:00 pm. Calves that could not drink milk properly were fed using a bottle. On the 4th day of birth, calves were fed from a milk bucket, which was provided throughout the day. Water was supplied to the calves on the third day after birth. The freely available drinking water was warm water in winter, and provided 24 hours a day. Calves are fed daily according to standard (Table 1).

\section{Sample collection and processing}

\section{Feed intake}

During the test period, the amount of feed and the amount of feed remaining were accurately recorded every day.

\section{Weight and body size measurement}

The whole body size was measured by the same person before and after the trial .

Body height: The vertical distance from the highest point of the withers to the ground, measured with a measuring stick.

Body length: the distance from the shoulder to the end of the ischial bone, measured with a tape measure.

Chest circumference: The vertical circumference of the body at the posterior horn of the shoulder blade, measured with a tape measure.

Cannon circumference: The circumference measured at one third of the forelimb cannon bone, measured with a tape measure.

Body weight was measured before and after the treatments.

\section{Blood collection and sample preparation}


The trial lasted 70 days. We collected $20 \mathrm{~mL}$ jugular venous blood in the morning at 7,15 and 60 days old per cow. After the blood was collected, it was placed in a coagulation tube and allowed to stand at room temperature for $30 \mathrm{~min}$. When the serum was precipitated, it was centrifuged at $3000 \mathrm{r} / \mathrm{min}$ for 15 min in a low-speed centrifuge, and the serum was aspirated by a pipette and dispensed into a $1.5 \mathrm{~mL}$ centrifuge tube and stored at $-20^{\circ} \mathrm{C}$.

\section{Collection of rumen fluid}

Week 10 ended, squeezed rumen fluid from the rumen chyme after slaughter, filtered through four layers of gauze, and placed in a $5 \mathrm{~mL}$ cryotube, placed at $-80^{\circ} \mathrm{C}$ for testing.

\section{Sample analysis}

\section{Analysis of microbial diversity in rumen fluid based on $16 \mathrm{~S}$ rDNA V3+V4 region}

After extracting the total DNA of the sample, primers were designed according to the conserved regions; sequencing primers were added at the end of the primers. PCR amplification was carried out, and the products were purified, quantified and homogenized to form a sequencing library, which was sequenced on the Illumina HiSeq 2500. The sequences were clustered at a level of similarity of $97 \%$.

\section{Metabolomics analysis of rumen fluid based on LC-MS}

Samples were analyzed with the Agilent 1290 UHPLC Ultra High Liquid Meter and AB 5600 Triple TOF Mass Spectrometer. The results were analyzed by statistical methods using orthogonal projections to latent structures-disciplinant analysis (OPLS-DA). Differential metabolites were screened by combining the $P$ value of the Student's t-test with the VIP value of the OPLS-DA model. The criteria for screening were $P$ value $<0.05$ and VIP $>1.5$.

\section{Data analysis}

The raw data was statistically processed using EXCEL. The data was analyzed using the one-way ANOVA model in SAS 8.2 software and compared using Duncan's multiple range test. $P<0.01$ indicates that the difference is extremely significant, $0.01<P<0.05$ indicates that the difference is significant, and $0.05<P<0.1$ indicates that there is a tendency of difference, and the result is expressed in the form of means \pm SEMs.

\section{Abbreviations}

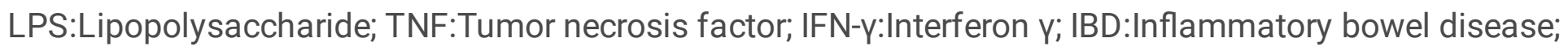
CD:Crohn's disease; ICLO:Intracellular Campylobacter-like organism; NDF:Neutral detergent fibre; EGT:Ergosine; LC-MS:Agilent 1290 UHPLC Ultra High Liquid Meter and AB 5600 Triple TOF Mass Spectrometer; OPLS-DA:Orthogonal projections to latent structures-disciplinant analysis; Ig:Immunoglobulin;IL:Interleukin-1;GH:Growth hormone; LP:Lipoprotein 


\section{Declarations}

\section{Ethics approval and consent to participate}

This study was carried out in accordance with the principles of the Basel Declaration and recommendations of Laboratory Animals-Guideline ,Welfare and Health Committee of Shandong Agricultural University.The protocol was approved by the ethics committee of Shandong Agricultural University. All study participants were consent to proceed with this project verbally. We also obtained written informed consent to use the cows in the study from the owner of the cows.

\section{Consent for publication}

Not applicable

\section{Availability of data and materials}

All data generated or analysed during this study are included in this published article [and its supplementary information files].

\section{Competing interests}

The authors declare that they have no competing interests.

\section{Funding}

The study was financially supported by the earmarked fund for 2017YFD0500502, Cattle Agro-industry Technology Research System of Shandong Province (SDAIT-12-011-06), Natural Science Fund of China (31572427) (31372340), National Key R \& D program of China , and Taishan scholar project. Funding bodies had no role in study design, data collection, analysis, and writing manuscript.

\section{Authors' contributions}

WZ and LX put forward the methodology and designed this work. ZT and JY were major contributors in writing the manuscript. $\mathrm{HQ}$ and $\mathrm{HZ}$ were mainly responsible for interpretation of data. WY and $\mathrm{HZ}$ reviewed and edited this article again.

All authors read and approved the final manuscript.

\section{Acknowledgements}

Not applicable

\section{References}


1. Saleem, F., Ametaj, B. N., Bouatra, S., Mandal, R. , Zebeli, Q., \& Dunn, S. M., et al. A metabolomics approach to uncover the effects of grain diets on rumen health in dairy cows. Journal of Dairy Science.2012; 95: 6606-6623.

2. Saleem, F., Bouatra, S., Guo, A. C., \& Nikolaos Psychogios. The bovine ruminal fluid metabolome. Metabolomics.2013;9:360-378.

3. Costerton, J. W., Damgaard, H. N., \& Cheng, K. J. Cell envelope morphology of rumen bacteria. Journal of Bacteriology.1974;118:1132-1143.

4. Roitt, I. M., Brostoff, J., \& Male, D. K. Immunology (5th ed.). London: Mosby.1998.

5. Tizard, I. R. Immunity at body surfaces. Veterinary Immunology, an Introduction. W. B. Saunders Co., Philadelphia, PA.1996.Pages 237-

6. Krause, D. O., \& Russell, J. B. How many ruminal bacteria are there? Journal of Dairy Science.1996 ;79:1467-1475.

7. Van Glyswyk, N. O., Wejdemar, K., \& Kulander, K. Comparative growth rates of various rumen bacteria in clarified rumen fluid from cows and sheep fed different diets. Applied and Environmental Microbiology.1992;58: 99-105.

8. Soest, P. J. V. Nutritional ecology of the ruminant. Cornell University P. 1994;44:2552-2561.

9. Muscato, T. V., Tedeschi, L. O., \& Russell, J. B. The effect of ruminal fluid preparations on the growth and health of newborn, milk-fed dairy calves. Journal of Dairy Science.2002;85:648-656.

10. Weimer, P. Redundancy, resilience, and host specificity of the ruminal microbiota: Implications for engineering improved ruminal fermentations. Frontiers in Microbiology.2015;6:296.

11. Abecia, L., Martin-Garcia, A., Martinez, G., Newbold, C., \& Yanez-Ruiz, D. Nutritional intervention in early life to manipulate rumen microbial colonization and methane output by kid goats postweaning. Journal of Animal Science.2013;91:4832-4840.

12. Abecia, L., Ramos-Morales, E., Martinez-Fernandez, G., Arco, A., Martin-Garcia, A., Newbold, C., \& Yanez-Ruiz, D. Feeding management in early life influences microbial colonisation and fermentation in the rumen of newborn goat kids. Animal Production Science.2014; 54:1449-1454.

13. Yanez-Ruiz, D., Abecia, L., \& Newbold, C. Manipulating rumen microbiome and fermentation through interventions during early life: A review. Frontiers in Microbiology.2015;6:1133.

14. Morgavi, D., Rathahao-Paris, E., Popova, M., Boccard, J., Nielsen, K., \& Boudra, H. Rumen microbial communities influence metabolic phenotypes in lambs. Frontiers in Microbiology.2015;6.

15. James, R. E., Polan, C. E., Bibb, T. L., \& Laughon, B. E. Effect of orally administered duodenal fluid on susceptibility of newborn calves to an escherichia coli challenge. Journal of Dairy Science.1976;59: 1495-1501.

16. Rey, M., Enjalbert, F., Combes, S., Cauquil, L., Bouchez, O., \& Monteils, V. Establishment of ruminal bacterial community in dairy calves from birth to weaning is sequential. Journal of Applied Microbiology.2014;116: 245-257. 
17. Jami, E., Israel, A. , Kotser, A., \& Mizrahi, I. Exploring the bovine rumen bacterial community from birth to adulthood. The ISME Journal.2013;7:1069-1079.

18. Zang Kaili, Jiang Yan, Sun Yong, et al. Probiotics modulate the structure and abundance of gut mircrobiota in populations with intestinal diseases. Food Science.2018;39: 133-143.

19. Vermeire, S., Joossens, M., Verbeke, K., Wang, J., Machiels, K., Sabino, J.,\& Raes, J. Donor species richness determines faecal microbiota transplantation success in inflammatory bowel disease. Journal of Crohn's and Colitis.2016;10:387-394.

20. Chen Yun, Liu Qi, Deng junliang, Yang Yanyi, Gao Shuang, Chen Chong, Yao Shuhua.Effects of composite antimicrobial peptide on rumen bacteria community structure of goat. Acta Agriculturae Zhejiangensis.2017;29: 1800-1808.

21. Schwarz, W. H.The cellulosome and cellulose degradation by anaerobic bacteria. Applied Microbiology \& Biotechnology.2001;56: 634-649.

22. Maki, M., Leung, K. T., \& Qin, W.The prospects of cellulase-producing bacteria for the bioconversion of lignocellulosic biomass. International Journal of Biological Sciences.2009;5: 500-516.

23. Xu J, Bjursell M K, Himrod J. A genomic view of the human-bacteroides thetaiotaomicron symbiosis. Science. 2003;299: 2074-2076.

24. Bäckhed, F., Ley, R. E., Sonnenburg, J. L., Peterson, D. A., \& Gordon, J. I. 2005.

25. Donaldson, G., Lee, S., \& Mazmanian, S.Gut biogeography of the bacterial microbiota. Nature Reviews Microbiology.2016;14: 20-32.

26. Hooda, S., Boler, B. M. V., Serao, M. C. R. , Brulc, J. M., Staeger, M. A., \& Boileau, T. W., et al.454 pyrosequencing reveals a shift in fecal microbiota of healthy adult men consuming polydextrose or soluble corn fiber. Journal of Nutrition. 2012;142: 1259-1265.

27. Gao R Y , Zhu Q C , Wu W, et al. .Compositional differences in fecal microbiota between rats with colorectal cancer and normal rats[J]. World Chinese Journal of Digestology. 2014;22:661-667.

28. Han Xufeng.Effects of age and dietary forage-to-concentrate rations on rumen microbial flora of the shanbei white-cashmere goat. Northwest A\&F University.2015

29. Gebhart, C. J., Barns, S. M., Mcorist, S., Lin, G. F., \& Lawson, G. H.lleal symbiont intracellularis, an obligate intracellular bacterium of porcine intestines showing a relationship to desulfovibrio species. International Journal of Systematic Bacteriology.1993;43: 533-538.

30. Howard, B. H., \& Hungate, R. E. Desulfovibrio of the sheep rumen. Applied and Environmental Microbiology. 1976;32: 598-602.

31. Gibson, G. R., Cummings, J. H., \& Macfarlane, G. T. Competition for hydrogen between sulphatereducing bacteria and methanogenic bacteria from the human large intestine. Journal of Applied Microbiology. 2010;65: 241-247.

32. Moore, W. E. C., J. L. Johnson, and L. V. Holdeman. Emendation of Bacteroidaceae and Butyrivibrio and descriptions of Desulfomonas gen. nov. and ten new species in the genera Desulfomonas, Butyrivibrio, Eubacterium, Clostridium, and Ruminococcus. Int. J. Syst. Bacteriol. 1976;26:238-252. 
33. Levine, U. Y., Bearson, S. M. D., \& Stanton, T. B. Mitsuokella jalaludinii inhibits growth of salmonella enterica serovar typhimurium. Veterinary Microbiology.2012;159:115-122.

34. Flint, H. J., Bayer, E. A., Rincon, M. T., Lamed, R., \& White, B. A.Polysaccharide utilization by gut bacteria: potential for new insights from genomic analysis. Nature Reviews Microbiology.2008;6:121131.

35. Lu Wenwei, Yang Zhennan, Ding Liwei, Ye Jiarong, Tian Fengwei, Chen Wei. Evaluation of Intestinal Microbiota in Mice after Oral Administration of Lactobacillus paracasei LC01. Food Science.2016;37: 230-235.

36. Zhang Xuejiao, Wang Lizhi.Effects of Dietary Neutral Detergent Fibre Level on Structure and Composition of rumen Bacteria in Goats. Journal of Animal Nutrition. 2018;30: 1377-1386.

37. Bladen H A, Bryant M P, Doetsch R N. A Study of Bacterial Species from the Rumen Which Produce Ammonia from Protein Hydrolyzate.. Appl Microbiol.1961;9:175-180.

38. Mcalian, A. B., \& Smith, R. H. Degradation of nucleic acids in the rumen. British Journal of Nutrition. 1973;29: 331-345.

39. Coleman, G. S. The cellulase content of 15 species of entodiniomorphid protozoa, mixed bacteria and plant debris isolated from the ovine rumen. The Journal of Agricultural Science.1985; 104: 349360 .

40. Abdelal, A. T. Arginine catabolism by microorganisms. Annual Review of Microbiology. 1979;33: 139168.

41. Cunin, R., Glansdorff, N., Piérard A, \& Stalon, V. Biosynthesis and metabolism of arginine in bacteria. Microbiological Reviews. 1986;50:314-352.

42. Haas D, Galimand M, Gamper M, Zimmermann A. Arginine network of Pseudomonas aeruginosa: specific and global controls. In: Silver S, Chakraberty AM, Iglewski B, Kaplan S(eds) Pseudomonas: biotransformations, pathogenesis, and evolving biotechnology. ASM Press, Washington DC. 1990;303-316.

43. Itoh, Y., \& Nakada, Y. Arginine and Polyamine Metabolism. Pseudomonas.2004;243-272.

44. Lu, C. D. Pathways and regulation of bacterial arginine metabolism and perspectives for obtaining arginine overproducing strains. Applied Microbiology and Biotechnology. 2006;70: 261-272.

45. Shi, D., Morizono, H., Yu, X., Roth, L., Caldovic, L., \& Allewell, N. M., et al. Crystal structure of nacetylornithine transcarbamylase from xanthomonas campestris: a novel enzyme in a new arginine biosynthetic pathway found in several eubacteria. Journal of Biological Chemistry. 2005;280: 1436614369.

46. Shi, D., Gallegos, R., Deponte, R. J., Morizono, H., Yu, X., \& Allewell, N. M., et al. Crystal structure of a transcarbamylase-like protein from the anaerobic bacterium bacteroides fragilis at 2.0 a resolution. Journal of Molecular Biology. 2002;320: 899-908.

47. Rahman, I., Gilmour, P., Jimenez, L., Biswas, S., Antonicelli, F., \& Aruoma, O. Ergothioneine inhibits oxidative stress- and TNF-alpha-induced NF-kappa B activation and interleukin-8 release in alveolar epithelial cells. Biochemical and Biophysical Research Communications. 2003;302: 860-864. 
48. Pfeiffer, C., Bauer, T., Surek, B., Sch?Mig, E., \& Dirk GrüCyanobacteria produce high levels of ergothioneine. Food Chemistry. 129:2011;1766-1769.

49. Seebeck,F., \& Florian, P. In vitro reconstitution of mycobacterial ergothioneine biosynthesis. Journal of the American Chemical Society.2010;132:6632-6633.

50. Van, D. H. C., Oyaert, W., \& Bouckaert, J. H. Fermentation of histidine by rumen bacteria. Research in Veterinary Science.1963;4:77-88.

51. Broderick G A, Wallace R J, Ørskov E R.Control of Rate and Extent of Protein Degradation. Physiological Aspects of Digestion \& Metabolism in Ruminants.1991;11:541-592.

\section{Tables}

Table 1 The amount of milk fed to the calves

\begin{tabular}{ccccccc}
\hline & \multicolumn{5}{c}{ Days } & \\
\cline { 3 - 6 } & $1-10$ & $11-20$ & $21-30$ & $31-40$ & $41-50$ & $51-55$ \\
\hline Milk & $4.5 \mathrm{~L}$ & $6.5 \mathrm{~L}$ & $8 \mathrm{~L}$ & $8.5 \mathrm{~L}$ & $4 \mathrm{~L}$ & $3 \mathrm{~L}$ \\
\hline
\end{tabular}

Table 2 Effects of rumen fluid supplementation ways on growth performance of calves

\begin{tabular}{ccccc}
\hline & \multicolumn{3}{c}{ Group } & \multirow{2}{*}{$p$} \\
\cline { 2 - 4 } & $\mathrm{C}$ & $\mathrm{M}$ & \\
\cline { 2 - 4 } & & & \\
Before the experience & & & \\
Weight, kg & $40.38 \pm 1.16$ & $42.00 \pm 1.08$ & $44.38 \pm 3.13$ & 0.41 \\
Height, cm & $77.93 \pm 2.23$ & $76.25 \pm 1.75$ & $80.00 \pm 1.87$ & 0.43 \\
Length, cm & $68.00 \pm 1.91$ & $71.25 \pm 1.31$ & $69.75 \pm 1.44$ & 0.38 \\
Chest girth, cm & $79.00 \pm 0.91$ & $82.00 \pm 1.47$ & $82.50 \pm 2.10$ & 0.28 \\
After the experience & & & & \\
Weight, kg & $95.25 \pm 3.33^{\mathrm{b}}$ & $105.75 \pm 3.74^{\mathrm{ab}}$ & $112.50 \pm 4.26^{\mathrm{a}}$ & 0.03 \\
Daily gain, kg & $0.89 \pm 0.07^{\mathrm{b}}$ & $1.03 \pm 0.05^{\mathrm{ab}}$ & $1.10 \pm 0.04^{\mathrm{a}}$ & 0.07 \\
Height, cm & $93.43 \pm 2.63$ & $96.73 \pm 1.18$ & $99.68 \pm 1.84$ & 0.14 \\
Length, cm & $92.15 \pm 2.47$ & $93.86 \pm 0.99$ & $98.22 \pm 2.76$ & 0.19 \\
Chest girth, cm & $108.60 \pm 0.98$ & $112.20 \pm 1.50$ & $112.75 \pm 2.45$ & 0.35 \\
Daily intake, g & $373.47 \pm 95.41$ & $443.58 \pm 54.54$ & $579.87 \pm 60.50$ & 0.18 \\
\hline
\end{tabular}

Notes: In the same row, values with different letter superscripts are significantly different $(P<0.05)$. 
Table 3 Effects of rumen fluid supplementation method on serum of calves

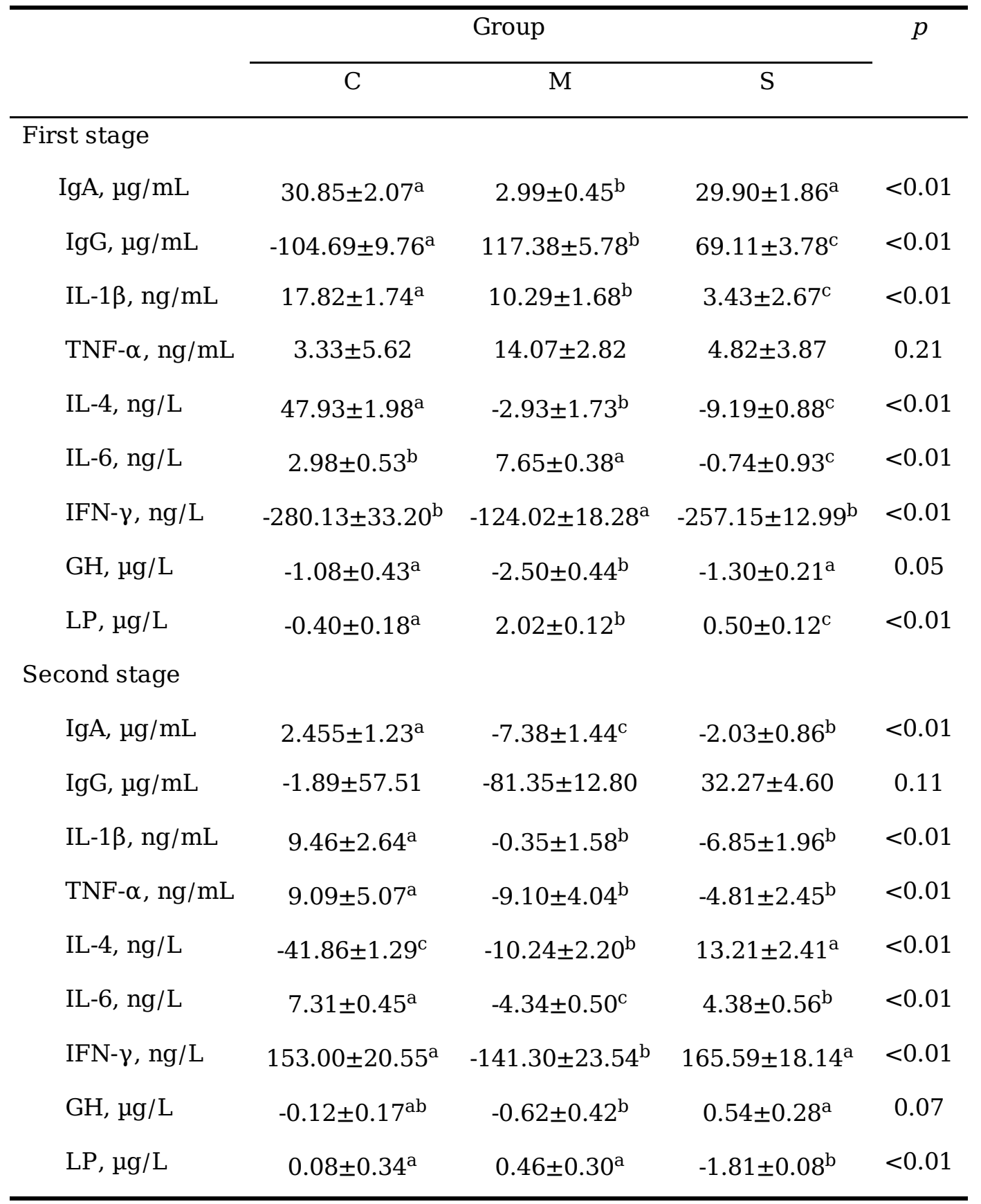

Notes: In the same row, values with different letter superscripts are significantly different $(P<0.05)$.

The numerical magnitude represents the amount of change at two points in time, positive or negative indicating an increase or decrease. The first stage was from 7 days to 15 days of age, indicating tests of serum indicators after treatment; the second stage was from 15 days to 63 days of age, indicating treatment for a period of time until the serum indices change after weaning.

Table 4 Differences of bacterial contents in rumen fluid (C-M) 


\begin{tabular}{|c|c|c|c|c|c|}
\hline Bacterium & \multicolumn{5}{|c|}{ Mean $\square \mathrm{C} \square$ Std.err $\square \mathrm{C} \square \mathrm{Mean} \square \mathrm{M} \square$ Std.err $\square \mathrm{M} \square \quad P$} \\
\hline \multicolumn{6}{|c|}{ Phylun } \\
\hline Firmicutes & 31.20 & 3.68 & 49.00 & 6.89 & 0.03 \\
\hline \multicolumn{6}{|c|}{ Class } \\
\hline Negativicutes & 13.00 & 3.46 & 27.80 & 7.69 & 0.10 \\
\hline \multicolumn{6}{|c|}{ Order } \\
\hline Selenomonadales & 13.00 & 3.46 & 27.80 & 7.69 & 0.07 \\
\hline \multicolumn{6}{|c|}{ Family } \\
\hline Ruminococcaceae & 4.02 & 0.93 & 10.10 & 1.82 & 0.01 \\
\hline uncultured_bacterium_o_Gastranaerophilales & 0.01 & 0.00 & 0.14 & 0.06 & 0.02 \\
\hline p-2534-18B5_gut_group & 0.49 & 0.17 & 0.08 & 0.05 & 0.02 \\
\hline Oxalobacteraceae & 0.00 & 0.00 & 0.02 & 0.01 & 0.03 \\
\hline Veillonellaceae & 9.53 & 3.64 & 25.40 & 7.53 & 0.06 \\
\hline Porphyromonadaceae & 0.02 & 0.01 & 0.01 & 0.00 & 0.10 \\
\hline \multicolumn{6}{|c|}{ Genus } \\
\hline uncultured_bacterium_o_Gastranaerophilales & 0.01 & 0.00 & 0.14 & 0.06 & 0.02 \\
\hline [Eubacterium]_coprostanoligenes_group & 0.05 & 0.02 & 0.19 & 0.06 & 0.02 \\
\hline Oxalobacter & 0.00 & 0.00 & 0.02 & 0.01 & 0.03 \\
\hline Dialister & 0.85 & 0.62 & 9.43 & 4.28 & 0.04 \\
\hline Selenomonas_1 & 0.10 & 0.05 & 0.00 & 0.00 & 0.05 \\
\hline [Eubacterium]_xylanophilum_group & 0.01 & 0.01 & 0.00 & 0.00 & 0.08 \\
\hline Moryella & 0.02 & 0.00 & 0.09 & 0.04 & 0.09 \\
\hline
\end{tabular}

Note:The table shows the taxonomic statistics of bacteria on rumen fluid bacteria content greater than $0.01 \%$.

Table 5 Differences of bacterial contents in rumen fluid (C-S) 


\begin{tabular}{|c|c|c|c|c|c|}
\hline Bacterium & \multicolumn{4}{|c|}{ Mean $\square$ C $\square$ Std.err $\square$ C $\square$ Mean $\square$ S $\square$ Std.err $\square$ S $\square$} & $P$ \\
\hline \multicolumn{6}{|c|}{ Class } \\
\hline Deltaproteobacteria & 1.34 & 0.33 & 0.47 & 0.17 & 0.03 \\
\hline \multicolumn{6}{|c|}{ Order } \\
\hline Desulfovibrionales & 1.29 & 0.30 & 0.47 & 0.17 & 0.03 \\
\hline \multicolumn{6}{|c|}{ Family } \\
\hline uncultured_bacterium_o_Gastranaerophilales & 0.01 & 0.00 & 0.18 & 0.06 & 0.01 \\
\hline Desulfovibrionaceae & 1.29 & 0.30 & 0.47 & 0.17 & 0.03 \\
\hline Oxalobacteraceae & 0.00 & 0.00 & 0.15 & 0.01 & 0.03 \\
\hline \multicolumn{6}{|c|}{ Genus } \\
\hline Ruminococcaceae_NK4A214_group & 0.16 & 0.03 & 0.05 & 0.02 & 0.01 \\
\hline uncultured_bacterium_o_Gastranaerophilales & 0.01 & 0.00 & 0.18 & 0.06 & 0.01 \\
\hline uncultured_bacterium_f_Erysipelotrichaceae & 0.00 & 0.00 & 0.02 & 0.00 & 0.02 \\
\hline Desulfovibrio & 1.29 & 0.30 & 0.47 & 0.17 & 0.02 \\
\hline Dialister & 0.85 & 0.62 & 7.59 & 2.77 & 0.03 \\
\hline Oxalobacter & 0.00 & 0.00 & 0.02 & 0.01 & 0.03 \\
\hline [Ruminococcus]_gauvreauii_group & 0.19 & 0.05 & 0.07 & 0.02 & 0.04 \\
\hline Mitsuokella & 0.14 & 0.08 & 0.32 & 0.03 & 0.04 \\
\hline Prevotella_7 & 17.80 & 9.14 & 38.00 & 2.91 & 0.04 \\
\hline Selenomonas & 2.06 & 0.75 & 0.44 & 0.25 & 0.05 \\
\hline Ruminococcaceae_UCG-014 & 2.59 & 0.50 & 6.37 & 1.80 & 0.05 \\
\hline Selenomonas_1 & 0.10 & 0.05 & 0.00 & 0.00 & 0.05 \\
\hline Veillonellaceae_UCG-001 & 0.14 & 0.07 & 0.00 & 0.00 & 0.06 \\
\hline uncultured_rumen_bacterium & 0.58 & 0.18 & 0.20 & 0.09 & 0.06 \\
\hline Schwartzia & 0.07 & 0.04 & 0.00 & 0.00 & 0.08 \\
\hline
\end{tabular}

Note:The table shows the taxonomic statistics of bacteria on rumen fluid bacteria content greater than $0.01 \%$.

Table 6 Differences of bacterial contents in rumen fluid (M-S) 


\begin{tabular}{|c|c|c|c|c|c|}
\hline Bacterium & \multicolumn{5}{|c|}{$\mathrm{Mean} \square \mathrm{M} \square$ Std.err $\square \mathrm{M} \square \mathrm{Mean} \square \mathrm{S} \square \mathrm{Std}$.err $\square \mathrm{S} \square P$} \\
\hline \multicolumn{6}{|c|}{ Phylun } \\
\hline Synergistetes & 0.16 & 0.06 & 0.03 & 0.02 & 0.04 \\
\hline Bacteroidetes & 38.7 & 2.63 & 51.9 & 6.85 & 0.08 \\
\hline \multicolumn{6}{|c|}{ Class } \\
\hline Synergistia & 0.16 & 0.06 & 0.03 & 0.02 & 0.05 \\
\hline Bacteroidia & 38.7 & 2.63 & 51.9 & 6.84 & 0.08 \\
\hline \multicolumn{6}{|c|}{ Order } \\
\hline Synergistales & 0.16 & 0.06 & 0.03 & 0.02 & 0.05 \\
\hline Bacteroidales & 38.7 & 2.63 & 51.9 & 6.84 & 0.08 \\
\hline \multicolumn{6}{|c|}{ Family } \\
\hline Rikenellaceae & 0.78 & 0.17 & 2.31 & 0.64 & 0.03 \\
\hline p-2534-18B5_gut_group & 0.08 & 0.05 & 0.60 & 0.24 & 0.05 \\
\hline Synergistaceae & 0.16 & 0.06 & 0.03 & 0.02 & 0.05 \\
\hline \multicolumn{6}{|c|}{ Genus } \\
\hline [Ruminococcus]_gauvreauii_group & 0.16 & 0.02 & 0.07 & 0.02 & $<0.01$ \\
\hline Rikenellaceae_RC9_gut_group & 0.69 & 0.12 & 2.30 & 0.65 & 0.02 \\
\hline Syntrophococcus & 0.07 & 0.02 & 0.76 & 0.30 & 0.03 \\
\hline uncultured_bacterium_f_p-2534-18B5_gut_group & 0.03 & 0.03 & 0.53 & 0.23 & 0.03 \\
\hline Pyramidobacter & 0.16 & 0.06 & 0.03 & 0.02 & 0.04 \\
\hline Prevotella_7 & 23.6 & 6.50 & 38.00 & 2.91 & 0.04 \\
\hline
\end{tabular}

Note:The table shows the taxonomic statistics of bacteria on rumen fluid bacteria content greater than $0.01 \%$. able 7 Metabolites and their corresponding metabolic pathways (C-M) 


\begin{tabular}{|c|c|c|c|c|}
\hline Metabolite & Metabolic pathway & $\begin{array}{c}\text { Fold- } \\
\text { change }\end{array}$ & $P$ & VIP \\
\hline 5-Methylcytosine & Pyrimidine metabolism(ko00240) & 1.847 & 0.008 & 2.156 \\
\hline Xanthine & Purine metabolism(ko00230) & 2.285 & 0.005 & 2.138 \\
\hline L-Citrulline & $\begin{array}{l}\text { Biosynthesis of amino acids (ko01230); } \\
\text { Arginine biosynthesis(ko00220) }\end{array}$ & 2.083 & 0.008 & 2.085 \\
\hline Myo-Inositol & $\begin{array}{c}\text { Ascorbate and aldarate } \\
\text { metabolism(ko00053); } \\
\text { Inositol phosphate metabolism(ko00562); } \\
\text { Galactose metabolism(ko00052) }\end{array}$ & 1.619 & 0.044 & 1.916 \\
\hline 2-Isopropylmalic acid & $\begin{array}{l}\text { Biosynthesis of amino acids(ko01230); } \\
\text { 2-Oxocarboxylic acid metabolism(ko01210); } \\
\text { Valine leucine and isoleucine } \\
\text { biosynthesis(ko00290); } \\
\text { Pyruvate metabolism(ko00620) }\end{array}$ & 1.683 & 0.009 & 2.192 \\
\hline $\begin{array}{l}\text { 3-Methoxy-4- } \\
\text { hydroxyphenylethyleneglycol }\end{array}$ & Tyrosine metabolism(ko00350) & 1.449 & 0.009 & 2.093 \\
\hline Indoleacetic acid & Tryptophan metabolism(ko00380); & 1.236 & 0.040 & 1.813 \\
\hline Deoxyadenosine & Purine metabolism(ko00230) & 1.560 & 0.013 & 2.023 \\
\hline Erucic acid & $\begin{array}{c}\text { Biosynthesis of unsaturated fatty } \\
\text { acids(ko01040) }\end{array}$ & 1.288 & 0.037 & 1.856 \\
\hline UDP-D-Galactose & $\begin{array}{l}\text { Galactose metabolism(ko00052); } \\
\text { Amino sugar and nucleotide sugar } \\
\text { metabolism(ko00520) }\end{array}$ & 2.222 & 0.017 & 1.894 \\
\hline Myristic acid & Fatty acid biosynthesis(ko00061) & 0.767 & 0.046 & 1.775 \\
\hline Uracil & $\begin{array}{c}\text { beta-Alanine metabolism(ko00410); } \\
\text { Pyrimidine metabolism(ko00240); } \\
\text { Pantothenate and CoA biosynthesis(ko00770) }\end{array}$ & 1.763 & 0.046 & 2.236 \\
\hline Homovanillic acid & Tyrosine metabolism(ko00350) & 1.260 & 0.009 & 2.472 \\
\hline Thiamine & Thiamine metabolism(ko00730) & 0.474 & 0.022 & 2.323 \\
\hline
\end{tabular}

Table 8 Metabolites and their corresponding metabolic pathways (C-S) 


\begin{tabular}{|c|c|c|c|c|}
\hline Metabolite & Metabolic pathway & $\begin{array}{c}\text { Fold- } \\
\text { change }\end{array}$ & $P$ & VIP \\
\hline Cytidine & Pyrimidine metabolism(ko00240) & 1.856 & 0.027 & 1.904 \\
\hline D-Ribulose 5-phosphate & $\begin{array}{c}\text { Pentose phosphate pathway(ko00030); } \\
\text { Vitamin B6 metabolism(ko00750); } \\
\text { Riboflavin metabolism(ko00740); } \\
\text { Carbon metabolism(ko01200); } \\
\text { Biosynthesis of amino acids(ko01230); } \\
\text { Pentose and glucuronate interconversions (ko00040) }\end{array}$ & 3.198 & 0.025 & 2.002 \\
\hline Ergothioneine & Histidine metabolism(ko00340) & 2.166 & 0.032 & 1.883 \\
\hline $\begin{array}{l}\text { Thymidine 5'- } \\
\text { monophosphate }\end{array}$ & Pyrimidine metabolism(ko00240) & 1.543 & 0.049 & 1.752 \\
\hline $\begin{array}{l}\text { Cytidine } 5^{\prime}- \\
\text { monophosphate }\end{array}$ & Pyrimidine metabolism(ko00240) & 1.816 & 0.007 & 2.145 \\
\hline UDP-D-Galactose & $\begin{array}{l}\text { Amino sugar and nucleotide sugar } \\
\text { metabolism(ko00520); } \\
\text { Galactose metabolism(ko00052) }\end{array}$ & 2.113 & 0.022 & 1.932 \\
\hline 5-Aminopentanoic acid & $\begin{array}{l}\text { Arginine and proline metabolism(ko00330); } \\
\text { Lysine degradation(ko00310) }\end{array}$ & 0.639 & 0.030 & 1.855 \\
\hline Uracil & $\begin{array}{c}\text { Pantothenate and CoA biosynthesis(ko00770); } \\
\text { Pyrimidine metabolism(ko00240); } \\
\text { Beta-alanine metabolism(ko00410) }\end{array}$ & 1.900 & 0.039 & 1.894 \\
\hline Urocanic acid & Histidine metabolism(ko00340) & 2.079 & 0.031 & 1.945 \\
\hline Xanthine & Purine metabolism(ko00230) & 1.629 & 0.016 & 2.063 \\
\hline N-Acetyl-L-glutamate & $\begin{array}{c}\text { 2-Oxocarboxylic acid metabolism(ko01210); } \\
\text { Arginine biosynthesis (ko00220); } \\
\text { Biosynthesis of amino acids(ko01230) }\end{array}$ & 1.392 & 0.028 & 1.977 \\
\hline Cytidine & Pyrimidine metabolism(ko00240) & 1.744 & 0.035 & 1.899 \\
\hline Salidroside & Tyrosine metabolism(ko00350) & 1.879 & 0.047 & 1.831 \\
\hline
\end{tabular}

\section{Supplementary Table}

Supplementation 1 Serum indicators of calves at 7 days of age 


\begin{tabular}{ccccc}
\hline & \multicolumn{3}{c}{ Group } & \multirow{2}{*}{$P$} \\
\cline { 2 - 4 } & $\mathrm{C}$ & $\mathrm{M}$ & $\mathrm{S}$ & \\
\hline IgA, $\mu \mathrm{g} / \mathrm{mL}$ & $41.04 \pm 1.13^{\mathrm{b}}$ & $49.17 \pm 0.82^{\mathrm{a}}$ & $27.70 \pm 1.00^{\mathrm{c}}$ & $\square 0.01$ \\
$\mathrm{IgG}, \mu \mathrm{m} / \mathrm{mL}$ & $559.05 \pm 10.87^{\mathrm{a}}$ & $341.08 \pm 5.81^{\mathrm{b}}$ & $314.26 \pm 4.22^{\mathrm{c}}$ & $\square 0.01$ \\
$\mathrm{IL}-1 \beta, \mathrm{ng} / \mathrm{mL}$ & $49.22 \pm 2.51^{\mathrm{b}}$ & $50.23 \pm 0.61^{\mathrm{b}}$ & $60.65 \pm 0.89^{\mathrm{a}}$ & $\square 0.01$ \\
$\mathrm{TNF}-\alpha, \mathrm{ng} / \mathrm{mL}$ & $52.18 \pm 1.66^{\mathrm{b}}$ & $53.66 \pm 3.96^{\mathrm{ab}}$ & $58.62 \pm 2.03^{\mathrm{a}}$ & 0.09 \\
$\mathrm{IL}-4, \mathrm{ng} / \mathrm{L}$ & $58.58 \pm 1.69^{\mathrm{d}}$ & $90.23 \pm 1.45^{\mathrm{b}}$ & $66.77 \pm 2.13^{\mathrm{c}}$ & $\square 0.01$ \\
$\mathrm{IL}-6, \mathrm{ng} / \mathrm{L}$ & $13.30 \pm 0.59^{\mathrm{b}}$ & $13.46 \pm 0.20^{\mathrm{b}}$ & $18.12 \pm 0.50^{\mathrm{a}}$ & $\square 0.01$ \\
$\mathrm{IFN}-\gamma, \mathrm{ng} / \mathrm{L}$ & $749.93 \pm 27.41^{\mathrm{b}}$ & $926.36 \pm 18.73^{\mathrm{a}}$ & $881.68 \pm 9.03^{\mathrm{a}}$ & $\square 0.01$ \\
GH, $\mu \mathrm{gg} / \mathrm{L}$ & $15.24 \pm 0.19^{\mathrm{b}}$ & $18.51 \pm 0.34^{\mathrm{a}}$ & $16.18 \pm 0.43^{\mathrm{b}}$ & $\square 0.01$ \\
$\mathrm{LP}, \mu \mathrm{g} / \mathrm{L}$ & $6.68 \pm 0.11^{\mathrm{a}}$ & $5.00 \pm 0.21^{\mathrm{d}}$ & $6.18 \pm 0.07^{\mathrm{b}}$ & $\square 0.01$ \\
\hline
\end{tabular}

Notes: In the same row, values with different letter superscripts denote significant differences $(P<0.05)$.

\section{Figures}

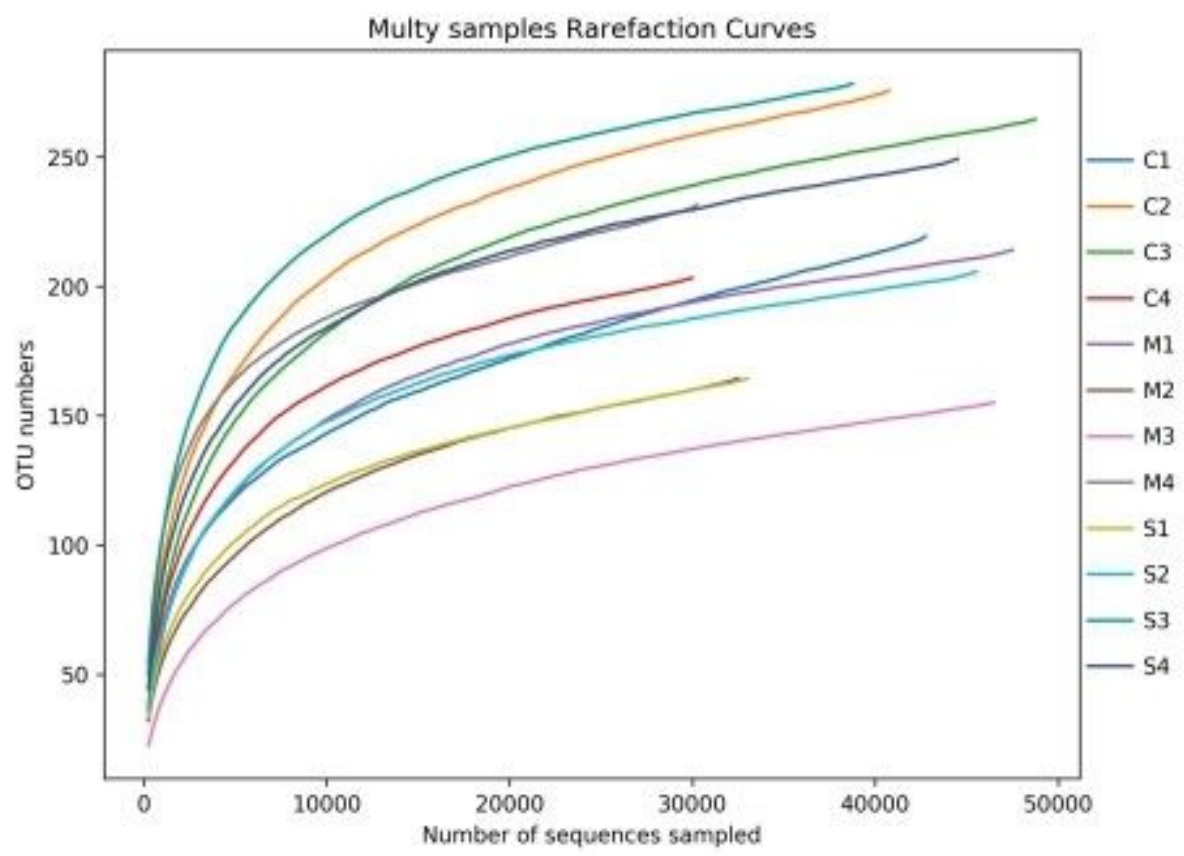

\section{Figure 1}

Sample-based rarefaction curve of observed species 

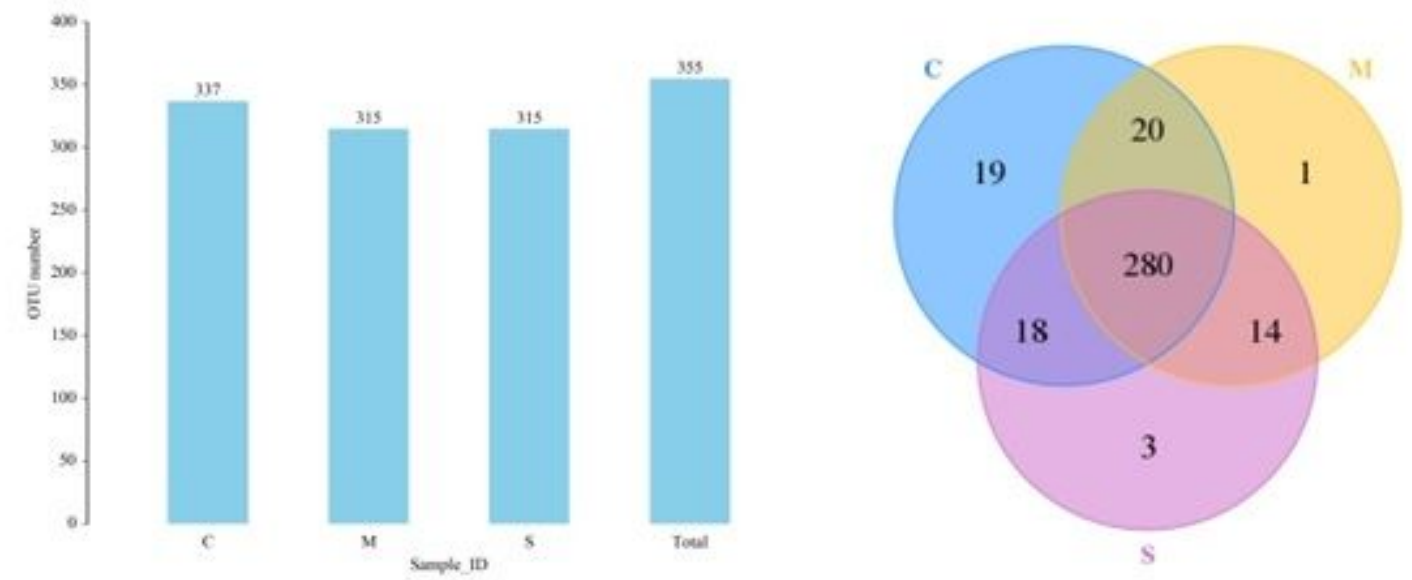

\section{Figure 2}

Shared OTU across different groups

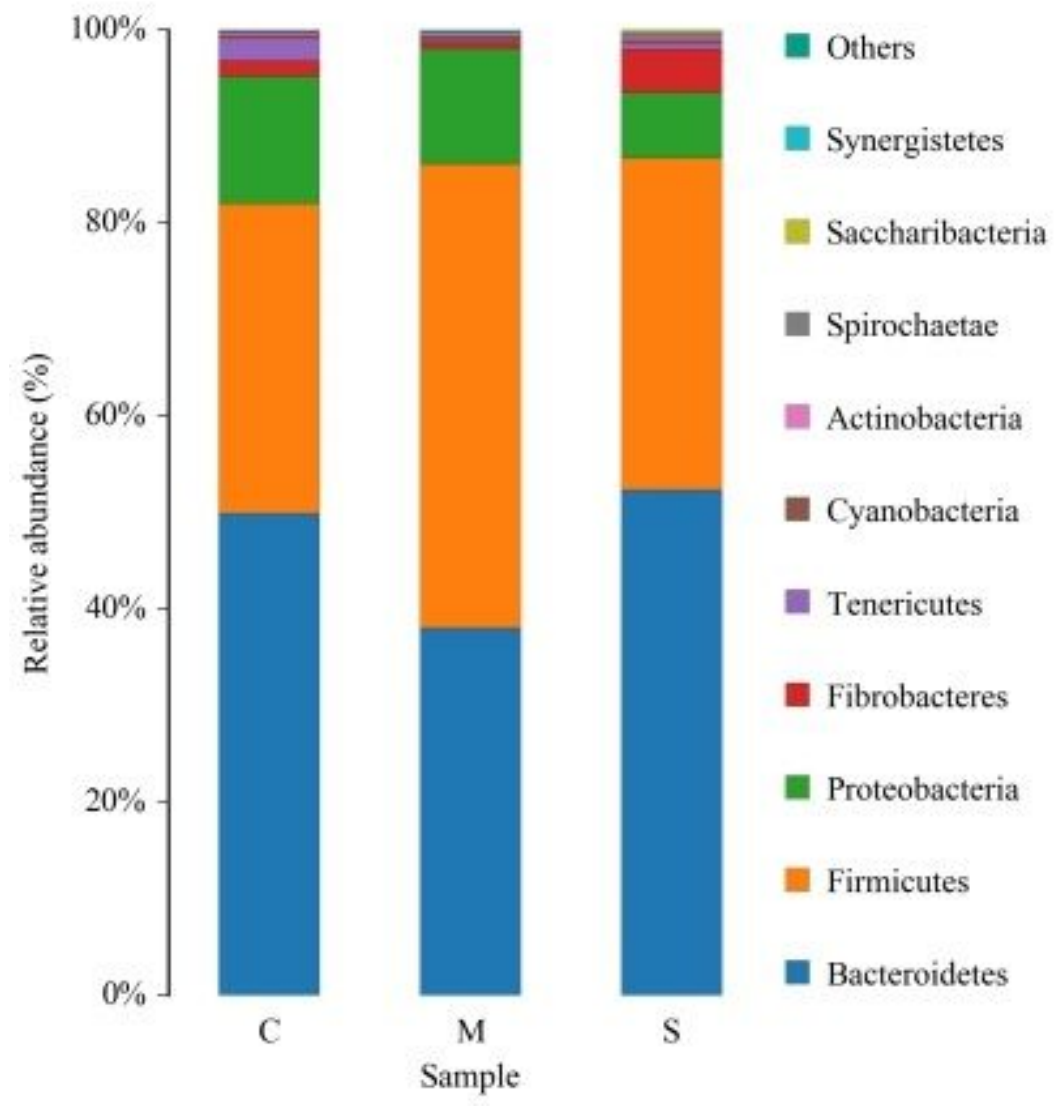

Figure 3

The taxonomic composition distribution in samples at the phylum-level 


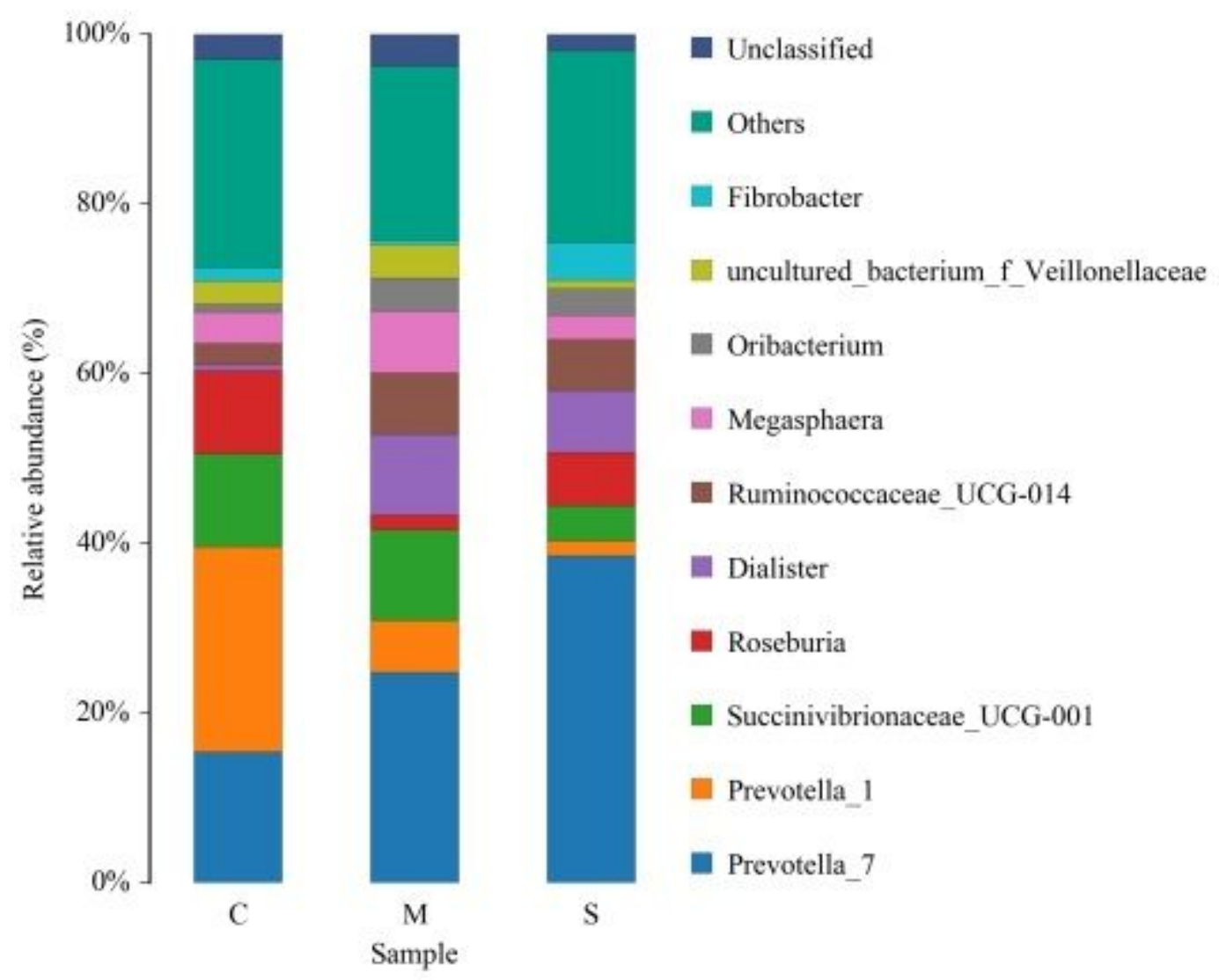

Figure 4

The taxonomic composition distribution in samples of genus-level 
Phylum

* Proteobacteria

- Fibrobacteres

- Bacteroidetes

A Tenericutes

Eirmicutes

- Other

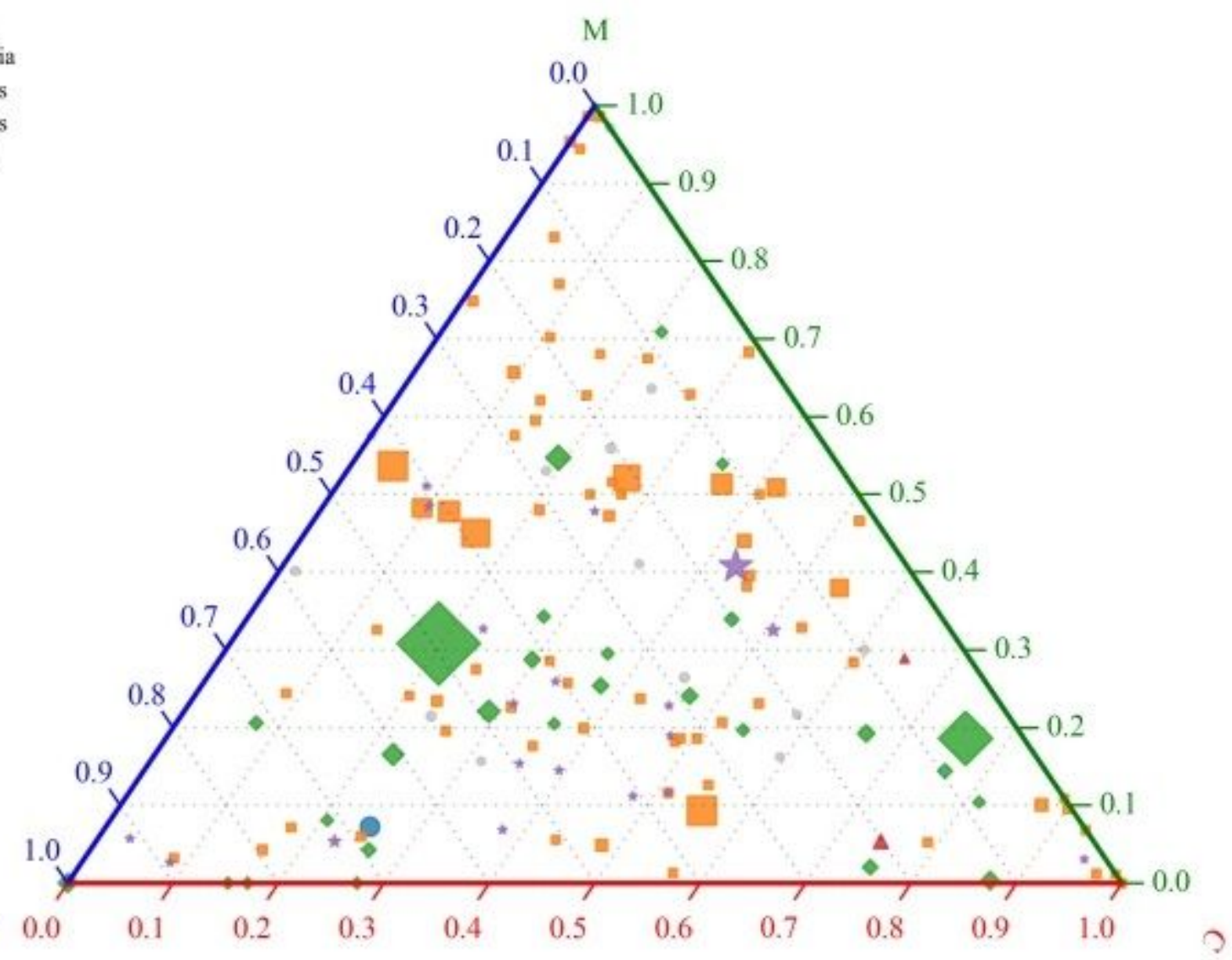

\section{Figure 5}

Ternary phase diagram
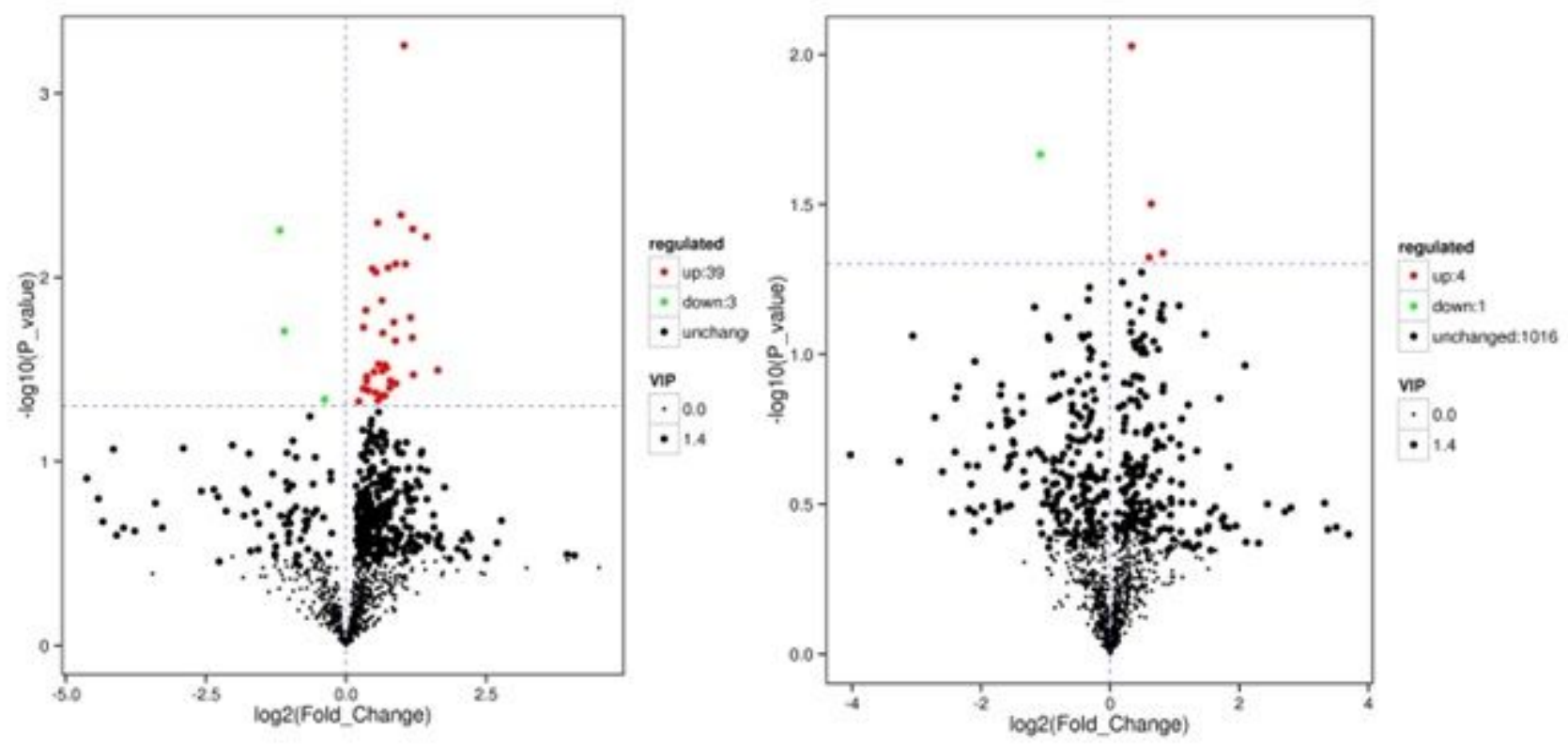
Figure 6

C_vs_M.volcano
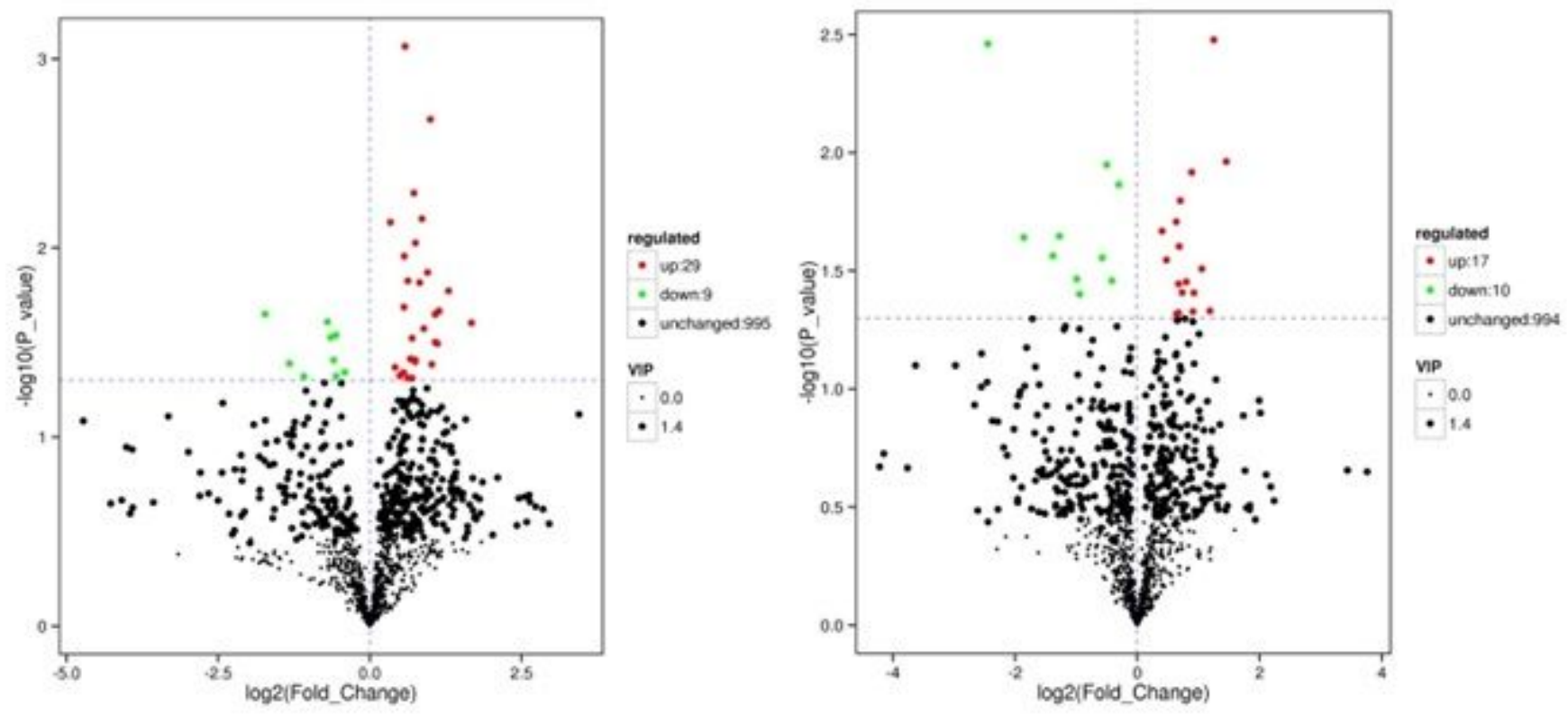

Figure 7

C_vs_S.volcano

\section{Supplementary Files}

This is a list of supplementary files associated with this preprint. Click to download.

- SI.docx 